\title{
Normative Data for the Stroop Color Word Test for a North American Population
}

\author{
Sarah A. Morrow
}

\begin{abstract}
Background: Cognitive impairment in multiple sclerosis (MS) often involves attentional deficits. The Stroop colour word test, a measure of attention, lacks current normative data for an English-speaking North American MS population. Further some authors suggest the Stroop actually measures processing speed. Objective: To generate normative data for the Stroop colour word test that can be used for a Canadian or North American MS population and to examine the relationship between processing speed tests - the Paced Auditory Serial Addition Test (PASAT) and Symbol Digit Modalities Test (SDMT) - and the Stroop. Results: Data from 146 healthy subjects aged 18-56 was collected. Age was significantly although weakly correlated with general intelligence $(\mathrm{r}=0.168, \mathrm{p}=0.043$ ) assessed with the North American Adult Reading Test (NAART), and education ( $\mathrm{r}=-0.313, \mathrm{p}<0.001)$. No demographic variables were associated with SDMT or PASAT. Age had a low-moderate negative correlation $(\mathrm{r}=-0.403, \mathrm{p}<0.001)$ with Stroop scores. The mean ( \pm standard deviation, SD) Stroop score was 45.4(10.4). The z-score can thus be calculated as [(X-45.4)/10.4]. If adjusted for age, Xadj $=[\mathrm{X}-(-0.47)($ age-37.5) $]$ and is substituted for X. In a comparison MS population consisting of 75 randomly selected patients from the MS Cognitive clinic, Stroop and PASAT performance were not related. A relationship existed between Stroop and SDMT scores but only $12.2 \%$ of the Stroop score variance was explained by the SDMT. Therefore, the Stroop measures selective attention independently of processing speed. Conclusion: This data can be used to determine impaired attention in MS patients.
\end{abstract}

RÉSUMÉ: Données normatives pour le test mot-couleur de Stroop chez une population nord-américaine. Contexte : Les troubles cognitifs dans la sclérose en plaques (SP) incluent souvent des déficits de l'attention. On ne possède pas de données normatives actuelles pour le test mot-couleur de Stroop, une mesure de l'attention, pouvant être utilisées chez une population nord-américaine de langue anglaise composée de patients atteints de la SP. De plus, certains auteurs suggèrent que le Stroop mesure réellement la rapidité de traitement. Objectif : Le but de l'étude était de générer des données normatives pour le test de Stroop qui puissent être utilisées chez une population canadienne ou nord-américaine de patients atteints de la SP et d'examiner la relation entre les tests de rapidité de traitement - le Paced Auditory Serial Addition Test (PASAT) et le Symbol Digit Modalities Test (SDMT) - et le Stroop. Résultats : Les données de 146 sujets sains âgés de 18 à 56 ans ont été recueillies. L'âge était significativement corrélé, bien que la corrélation soit faible, à l'intelligence générale $(\mathrm{r}=0,168 ; \mathrm{p}=0,043)$ évaluée au moyen du North American Adult Reading Test (NAART) et au niveau de scolarité $(\mathrm{r}=-0,313 ; \mathrm{p}<0,001)$. Aucune variable démographique n'était associée au SDMT ou au PASAT. L'âge était modérément corrélé négativement $(\mathrm{r}=-0,403 ; \mathrm{p}<0,001)$ au Stroop. La moyenne ( \pm l'écart type, ÉT) du score au test de Stroop était de 45,4 (ÉT 10,4). Le score z peut donc être calculé ainsi : $[(X-45,4) / 10,4]$ et, après ajustement pour l'âge, $X a=[X-(0,47)(a ̂ g e-37,5)]$ Xa étant substitué à X. La performance au Stroop et au PASAT n'étaient pas reliées chez une population de 75 patients atteints de SP choisis au hasard dans une clinique de psychologie cognitive dédiée aux patients atteints de SP. Il existait une relation entre le test de Stroop et le test SDMT, mais seulement 12,2\% de la variance du score au test de Stroop était expliquée par le SDMT. Le Stroop mesure donc l'attention sélective indépendamment de la rapidité de traitement. Conclusion : Ces données peuvent être utilisées pour identifier une altération de l'attention chez des patients atteints de SP.

Can J Neurol Sci. 2013; 40: 842-847

Cognitive dysfunction is known to be a devastating consequence of Multiple Sclerosis (MS), commonly affecting processing speed, episodic and working memory ${ }^{1,2}$. Despite a high prevalence of cognitive impairment, clinicians have a difficult time identifying mild to moderately impaired MS patients partly because cognitive changes tend to present as insidiously progressive while intellectual function and language function remains intact. Thus, a comprehensive battery of validated tests is needed to investigate the potential cognitive impairment in MS patients. There are two commonly used batteries to assess cognitive dysfunction in MS, both of which have normative data available: Rao's Brief Repeatable Battery (BRB) and the Minimal Assessment of Cognitive Function in MS (MACFIMS) $)^{1,3,4}$.
Selective attention can also be impaired in MS patients ${ }^{3,5}$ which is the ability to focus solely on what is important, thus suppressing irrelevant information ${ }^{6}$. Yet, neither of these batteries included a measure of attention. The Stroop colour word test is considered the gold standard of attentional

From the Department of Clinical Neurological Sciences, Western University, London, Ontario, Canada.

Received November 6, 2012. Final Revisions Submitted May 22, 2013. Correspondence to: Sarah A. Morrow, Department of Clinical Neurological Sciences, Western University, B10-105, LHSC-UH, 339 Windermere Road, London, Ontario, N6A 5A5, Canada. Email: smorrow8@uwo.ca. 
measures ${ }^{7-9}$. The Stroop was originally developed in $1935^{10}$. The most commonly used version is the Golden version, developed in 1978, where the score of interest is the "interference" task. The subject is given a card with colour names written in an incongruent ink colour; and the subject voices the ink colours, ignoring the written word. The number of correct responses in 45 seconds is recorded $^{6}$. It is a sensitive test for impaired concentration and difficulty in warding off distraction ${ }^{5}$ since reading, in literate adults, is a fast automatic process and difficult to inhibit. There is normative data from 1978 for a population ranging in age from 15-90 years based on 100 subjects. An additional 300 normal controls, collected over a 20 year span, were added to these data in $2002^{11}$. More recent standardized scores were developed for the older population ( $>55$ years) to be used in the dementia population ${ }^{12,13}$. There is currently no updated population that corresponds to an English-speaking, North American MS population. Golden found, in his 1978 normative data, that both gender and education were associated with Stroop scores ${ }^{6}$. Other published normative data found no influence of age in the older population ( $>65$ years), and only a small influence of age in a more broad sample of subjects aged $12-83^{14,15}$. Other published normative data found age, intellectual level and/or education to be related to Stroop scores ${ }^{16-18}$. Most of these norms were published many years ago and thus, it is unknown whether the data would still be considered valid for a contemporary, predominantly young (age 18-56) female population as education levels attained has risen significantly in the last three decades, especially in women. The updated Golden normalized data adjusted for both age and education since they were confounders in the original sample, although whether they were related to Stroop scores in this new sample was either not reported or not examined ${ }^{11}$. The lack of normalized data limits the ability of clinicians to distinguish normal vs. impaired selective attention in MS patients.

Several researchers hypothesized that the Stroop is measuring deficits in processing speed (PS) rather than selective attention in the MS population; others have postulated that working memory or executive function play a role, especially in the interference trial ${ }^{19,20}$. Both the BRB and the MACFIMS include two measures of processing speed: the Paced Auditory Serial Addition Test (PASAT) and the Symbol Digit Modalities Test $(\mathrm{SDMT})^{21-23}$ and thus PS is adequately assessed when this battery is administered. If the Stroop is simply another measure of PS, it would not be a useful independent test. However, if is measures selective attention independently of PS, Stroop scores would add another tool to identify MS patients with cognitive impairment who often have impairment in domains other than PS alone.

This study was designed to collect data from a cohort of "normal" controls representative of the healthy general population on the Stroop, PASAT and SDMT. These data would be used to generate normalized data to determine the degree of impairment when testing our MS population with the Stroop colour word test. Further, it would be used to examine the correlation between Stroop scores and two conventional tests of PS to compare the relationship between PS and selective attention. Since most cognitively impaired MS patients have some degree of PS impairment ${ }^{4}$, using a normal population to delineate the contribution of PS and attention to the Stroop removes this confounder. Finally, in a random sample of MS patients with varying degrees of cognitive impairment, abnormal Stroop scores based on the normal data obtained in this study will be compared with abnormal SDMT and PASAT scores to determine the relationship between these cognitive tests.

\section{Methods \\ Participants - Normal Controls}

Subjects aged 18-56 were recruited using posters in medical clinics, online advertisements and social networking sites from October 2011 to December 2011. Subjects with a history of drug/alcohol abuse, psychiatric disorders, attention deficit (hyperactivity) disorder, learning disability, any neurologic disease with the potential to cause cognitive impairment (i.e. Alzheimer's disease/mild cognitive impairment, or traumatic head injury) or a major medical illness were excluded. Normal vision, at least 20/70 corrected and normal colour vision, and hearing was required.

\section{Participants - MS patients}

To determine whether the Stroop colour word test is simply measuring processing speed in the MS population, rather than selective attention, 75 MS patients assessed in the cognitive MS clinic for clinical reasons were randomly selected for comparison. Multiple Sclerosis patients aged 18-56 were included if they had all three tests (SDMT, PASAT and Stroop) administered, without evidence of severe depression determined either by clinical assessment or a score on the Beck Depression Inventory, Fast Screen (BDIFS) ${ }^{24}$ of 12 or less (excluding subjects with severe depression), had an Fatigue Severity Scale (FSS) score less than 6.0 (excluding subjects with severe fatigue $)^{25}$, and no history of any other medical reason that could impair cognitive function, as delineated above. This population did not differ significantly from the normal controls on demographic characteristics.

\section{Procedures and Measures}

The subjects were interviewed regarding their demographics, including age, gender, years of education achieved, and ethnicity. Information regarding past medical history, current medical conditions and medication use (prescribed and over the counter) were also obtained during the interview. Birth control medication, thyroid replacement, over the counter pain medication and medication for hypertension were allowed; all other medications and conditions were excluded. The North American Adult Reading Test (NAART), a measure of general intelligence ${ }^{26}$, was administered. Unreported depression was assessed with the BDIFS.

The Golden version of the Stroop colour word test consists of three parts. In the first, the subject reads a list of colour names printed in black ink. Next, the subject is given a card with Xs in different colours of ink; he/she names the colour of the ink. Finally, the subject is given a card with colour names written in an incongruent ink colour. He/she voices the ink colours, ignoring the written word ${ }^{6,27}$. The number of correct responses in 45 seconds for the colour-word step is considered the "interference" component of the Stroop test. In this study, all 
three parts were administered but only the interference score was used as a measure of selective attention. A higher score indicates better selective attention.

To measure processing speed, the oral version of the Symbol Digit Modalities Test (SDMT) was used ${ }^{3}$. The subject voices the number associated with target symbols based on a grid printed at the top of the stimulus page. The score is based on the number of correct responses in 90 seconds. Rao's version of the Paced Auditory Serial Addition Test (PASAT), validated in the MS population, was used in this study $^{3}$. The PASAT also measures processing speed as well as working memory. Single digits are presented every three seconds; subjects are instructed to add each new digit to the one immediately preceding it and respond orally. Subjects must ignore the previous total and add the next two digits during the time allotted. A higher score on either test indicates better processing speed.

\section{Analysis}

\section{Calculating z-scores}

Distribution of the test results was assessed for normal distribution using the Kolmogorov-Smirnov test. The mean and standard deviation (SD) of this "normal control" population was determined in order to calculate a normalized score (z- score) for the Stroop test based on the following formula: (subject score mean)/SD. To examine the influence of demographic variables on test scores and identify potential confounders, Pearson's correlation or one-way analysis of variance (ANOVA) was use where appropriate. Any $\mathrm{p}$-value $\mathrm{p}=0.1$ or less was considered a potential confounder. If any subject characteristic was found to a potential confounder the score obtained for the Stroop test as determined by the analysis above; regression analysis was used

Table 1: Demographics of 146 healthy controls

\begin{tabular}{l|r}
\hline Demographic & \\
\hline Age (years) & $37.5 \pm 10.9$ \\
Mean \pm SD & $100(68.5)$ \\
\hline Sex N (\%) & $46(31.5)$ \\
Female & $131(89.7)$ \\
Male & $4(2.7)$ \\
\hline Ethnicity N (\%) & $10.7)$ \\
Caucasian & $10(6.9)$ \\
African Canadian & $131(89.7)$ \\
Native Canadian & $15(10.3)$ \\
Other & $14.3 \pm 2.1$ \\
\hline Born in Canada? N (\%) & $107.8 \pm 7.4$ \\
Yes & \\
No & $0(0-8)$ \\
\hline Education (years) & \\
Mean \pm SD &
\end{tabular}

NAART: North American Adult Reading Test; BDIFS: Beck

Depression Inventory-Fast Screen; N: number; SD: standard deviation to determine the beta coefficient (b). The corrected subject score was obtained in the following way: [raw patient score $\mathrm{b}^{*}$ (subject characteristic score-mean characteristic score)], and inserted into the formula above.

\section{Determining the contribution of processing speed to the Stroop scores}

To determine the potential influence of processing speed vs. selective attention on Stroop interference task scores (herein referred to only as Stroop or Stroop scores), correlation analysis between the raw scores on the Stroop and both the PASAT and SDMT was performed. If any demographic data was found to potentially confound the results of the PASAT or SDMT, the analysis was adjusted accordingly. All statistical analyses were performed using SPSS 18.0. In the MS subjects, chi-square was used to determine if there was a relationship between an impaired score on the Stroop and impaired SDMT and PASAT scores. A z-score of <-1.5 was considered abnormal as per the MACFIMS classification. Logistic regression was used to determine the contribution of the PASAT and SDMT to the variance in the Stroop scores.

This study was approved by the Research Ethics Board at the University of Western Ontario, London, ON Canada.

\section{RESULTS}

There were 146 normal subjects tested; the mean age was 37.5 years \pm 10.9 standard deviations $(\mathrm{SD})$ and $68.5 \%(\mathrm{n}=100)$ were female. The mean years of education achieved was $14.3 \pm$ 2.1 and a mean NAART score was $107.8 \pm 7.4$, indicating that the estimate of our sample's general intelligence was above average (NAART score of 100.0). The majority of subjects were Caucasian and born in Canada $(89.7 \%, n=131)$. Age was significantly correlated with NAART scores $(r=0.168, p=0.043)$ and education $(\mathrm{r}=-0.313, \mathrm{p}<0.001)$ but these were only weak correlations, as indicated by the low $\mathrm{r}$ score. There were no other significant relationships detected between demographics or subject characteristics (Table 1).

The mean SDMT score was 63.3 \pm 9.7 and the mean PASAT score of the healthy controls was $47.6 \pm 9.1$ similar to previously published English-language data ${ }^{3,28,29}$. The mean Stroop score was $45.4 \pm 10.4$ with a range of 21-85. Both the SDMT and the Stroop results were normally distributed with KolmogorovSmirnov test. The PASAT was not normally distributed $(p=0.005)$ which is not unexpected due to the ceiling effect of the test (a maximum score of 60). None of the demographic variables were significantly associated with SDMT or PASAT. Age was significantly associated with the Stroop scores $(\mathrm{p}=0.025)$ with a low-moderate negative correlation $(\mathrm{r}=-0.403$, $\mathrm{p}<0.001)$. Neither gender nor education was correlated with Stroop scores in this normal population.

Linear regression determined that age contributed $16.2 \%$ of the variance in Stroop scores for the healthy control group. The beta coefficient for age was $-0.403(\mathrm{p}<0.001)$. The $\mathrm{z}$-score, unadjusted for age, for the Stroop color word test can be calculated as $[(\mathrm{X}-45.4) / 10.4]$. Z-scores of -1.5 , which can be used to determine an abnormal score, was equivalent to a raw score of 30 , and thus any score less than 30 would be considered impaired. If adjusted for age, Xadj is calculated as [X-($0.40)$ (age-37.5)], and Xadj is substituted for $X$ in the above formula. 
Table 2: Pearson's correlations between the three administered tests in the normal control population

\begin{tabular}{l|l|l|l}
\hline & Stroop & SDMT & PASAT \\
\hline Stroop & --- & $r=0.514$ & $r=0.403$ \\
& & $p<0.001$ & $p<0.001$ \\
\hline SDMT & $r=0.514$ & -- & $r=0.333$ \\
& $p<0.001$ & & $p<0.001$ \\
\hline PASAT & $r=0.403$ & $r=0.333$ & --- \\
& $p<0.001$ & $p<0.001$ & \\
\hline
\end{tabular}

Stroop: Stroop colour word test; SDMT: Symbol Digit Modalities Test; PASAT: Paced Auditory Serial Addition Test

To determine the relationship between the PASAT, SDMT and Stroop and to determine the potential influence of processing speed vs. selective attention on Stroop scores, correlation analysis was performed. The PASAT and SDMT results were moderately but significantly correlated with each other $(\mathrm{r}=0.333$, $\mathrm{p}<0.001)$. Both tests of processing speed demonstrated moderately positive significant correlations with the Stroop, stronger with the SDMT $(r=0.514, p<0.001)$ than the PASAT $(r=0.403, p<0.001)$ (Table 2). Fisher's Exact test was used to determine if there was a relationship between an impaired score on the Stroop (age adjusted) and impaired SDMT and PASAT scores $(\mathrm{z}$-score $<-1.5)$; the Stroop score was not found to be

Table 4: Demographic and disease characteristics of the $\mathbf{7 5}$ randomly selected MS patients

\begin{tabular}{l|l}
\hline Demographic & \\
\hline $\begin{array}{l}\text { Age (years) } \\
\text { Mean } \pm \text { SD }\end{array}$ & $39.35 \pm 8.9$ \\
\hline Sex N(\%) & $56(74.7)$ \\
Female & $19(25.3)$ \\
Male & $14.1 \pm 2.2$ \\
\hline Education (years) & $105.2 \pm 8.6$ \\
Mean \pm SD & $3(3-11)$ \\
\hline NAART & $7.4 \pm 7.5$ \\
Mean \pm SD & $61(81.3)$ \\
\hline BDIFS & $7(9.3)$ \\
Median (range) & $3(4.0)$ \\
\hline Disease Duration & $4(5.3)$ \\
Mean \pm SD & $2.0(0-7.5)$ \\
\hline Type of MS &
\end{tabular}

NAART: North American Adult Reading Test; BDIFS: Beck

Depression Index Fast Screen; RR: relapsing remitting; SP: secondary progressive; PP: primary progressive; CIS: clinically isolated syndrome; EDSS: Expanded Disability Status Scale
Table 3: Classification as cognitively unimpaired or cognitively impaired in the normal control cohort

\begin{tabular}{l|l|l|l|l}
\hline & $\begin{array}{l}\text { SDMT } \\
\text { Normal }\end{array}$ & SDMT Impaired & PASAT Normal & $\begin{array}{l}\text { PASAT } \\
\text { Impaired }\end{array}$ \\
\hline Stroop Normal & 130 & 10 & 130 & 10 \\
\hline Stroop Impaired & 5 & 1 & 5 & 1 \\
\hline
\end{tabular}

Stroop: Stroop colour word test; SDMT: Symbol Digit Modalities Test; PASAT: Paced Auditory Serial Addition Test; Normal: z-score $\geq-1.5$ SD; Impaired: $\mathrm{z}$-score $<-1.5 \mathrm{SD}$

significantly predictive of either test (SDMT $\mathrm{p}=0.380$, PASAT $\mathrm{p}=0.380$ ) (Table 3$)$.

Finally, SDMT, PASAT and Stroop scores from the randomly selected MS patients were compared. The demographics and characteristics of this population are noted in Table 4. Impaired SDMT scores were found to be related to impaired Stroop scores $\left[\mathrm{X}_{2}(1, \mathrm{n}=75)=9.09, \mathrm{p}=0.003\right)$ while the impaired PASAT scores were not $\left(\mathrm{X}_{2}(1, \mathrm{n}=75)=2.75, \mathrm{p}=0.10\right)$. Logistic regression, using forward step (Wald), found the SDMT only accounted for $12.1 \%$ of the variation in Stroop scores while the PASAT did not significant explain any of the variance and was not added to the model. Overall, SDMT scores were not predictive of impairment on the Stroop test (Table 5).

\section{Discussion}

This study uses data from a healthy population to determine norms for the Stroop colour word test to provide data to better diagnose impaired selective attention in MS patients. Further, this study confirms a possible small contribution of processing speed to the performance on the Stroop in MS patients as the SDMT accounted for $12.1 \%$ of the variance in Stroop scores, but also demonstrates that the Stroop does measure selective attention independently of processing speed.

Selective attention, as previously defined, is the ability to focus solely on what is important, thus suppressing irrelevant information. It is known to be involved in traumatic brain injury and concussions, depression, mild cognitive impairment and dementia as well as many psychiatric disorders. The exact pathological cause of deficits in selective attention in MS

Table 5: Classification as cognitively unimpaired or cognitively impaired in the MS cohort

\begin{tabular}{l|l|l|l|l}
\hline & $\begin{array}{l}\text { SDMT } \\
\text { Normal }\end{array}$ & $\begin{array}{l}\text { SDMT } \\
\text { Impaired }\end{array}$ & $\begin{array}{l}\text { PASAT } \\
\text { Normal }\end{array}$ & $\begin{array}{l}\text { PASAT } \\
\text { Impaired }\end{array}$ \\
\hline Stroop Normal & 38 & 24 & 51 & 11 \\
\hline Stroop Impaired & 2 & 11 & 8 & 5 \\
\hline
\end{tabular}

Normal: z-score $\geq-1.5 \mathrm{SD}$; Impaired: z-score $<-1.5 \mathrm{SD}$ 
patients is not yet known. Studies using fMRI in both normal controls and MS patients without evidence of cognitive impairment demonstrate activation in several areas of the frontal and parietal lobes as well as the cerebellum ${ }^{30,31}$. Rovaris demonstrated a correlation between impaired performance on the Stroop and total lesion load and frontal lesion $\operatorname{load}^{32}$. Finally, MRS demonstrates a decrease in NAA/Cr levels in right hemipons as well as, globally MS patients demonstrating impaired attention ${ }^{33}$

It is not surprising that age was significantly associated with Stroop performance as other studies, detailed below, have shown a strong relationship between advancing age and decreased performance on measures of selective attention. In a study of older adults, age but not IQ, was found to be strongly associated with Stroop performance, while IQ was associated with measures of executive function and verbal fluency ${ }^{34}$. Another study comparing healthy controls' performance on the Stroop divided into ten year cohorts found a significant main effect for age, meaning a worsening of the score on the colour-word step with each older cohort ${ }^{35}$. As mentioned previously, the 1978 norms for the Golden version also found age to be associated with Stroop scores ${ }^{6}$. Our beta coefficient was found to be 0.4 , while both the 1978 and 2002 Golden norms use a beta coefficient of $0.23^{11}$, indicating that we found a stronger influence of age on the Stroop scores. This may reflect the age difference of our two populations, as the Golden norms included subjects aged 15-90, while we restricted our age group from 1856 , more in keeping with the MS population. Thus, it is important to interpret the performance of MS patients' on the Stroop in the context of age to account for any change that is due to the normal aging process as opposed to underlying MS pathology.

Processing speed in MS is the most common cognitive domain affected in the MS population, and presents as difficulty with multi-tasking, shifting attention and processing rapidly presented information ${ }^{2}$. The SDMT has been found to be a sensitive screening test for cognitive impairment in $\mathrm{MS}^{21,36}$ with reliable and valid results even when administered serially ${ }^{37,38}$. As mentioned previously, it has been hypothesized that the Stroop is measuring deficits in processing speed rather than selective attention in the MS population based on significant correlations found between measures of PS and the Stroop. However, these studies used only one of the two tests validated for MS patients ${ }^{39,40}$. A study by Bodling et al (2008) used performance on a PS test to predict Stroop scores; no statistical difference was found between MS subjects and normal controls in predicted and obtained reaction time, supporting the idea that the Stroop is a measure of $\mathrm{PS}^{41}$. However, the sample in this study was small $(n=25)$. This current study demonstrates that, although there is a contribution of PS to performance on the Stroop, this contribution is small and only occurs with the SDMT, which accounted for only $12.2 \%$ of the variance in Stroop scores in MS patients. It is possible that the overlap between the SDMT and Stroop is due to the visual administration of the two tests, as both require visual scanning. In contrast, the PASAT measures processing speed in the auditory domain. This study supports the use of a separate measure of selective attention apart from the SDMT in order to identify those MS patients who may have intact processing speed yet have attentional deficits.
It is important to be aware of the limitations of the Stroop test. Multiple sclerosis patients may have decreased vision due to optic neuritis' in the past or subclinical involvement of the optic nerve. Further, if the MS patient suffers from red-green colour blindness, the test cannot be performed. It is essential to have decreased visual acuity and/or colour vision prior to administering the Stroop.

\section{CONCLUSION}

This study provides data to calculate z-scores for the Stroop colour word test to be calculated in an English speaking North American population, thus allowing clinicians to better assess MS patients for impairment of selective attention. Although there may be some overlap between the cognitive domains used to perform the Stroop and the SDMT, the two tests are independent measures of selective attention and processing speed.

\section{ACKNowledgement / Disclosure}

This work was supported in part by an unrestricted educational grant from Novartis Canada.

The author thanks Dr. Andrew Johnson, PhD for his advice regarding the statistical analysis for this manuscript.

\section{REFERENCES}

1. Benedict RH, Fischer JS, Archibald CJ, et al. Minimal neuropsychological assessment of MS patients: a consensus approach. Clin Neuropsychol. 2002 Aug;16(3):381-97.

2. Rao SM. Neuropsychology of multiple sclerosis. Curr Opin Neurol. 1995 Jun;8(3):216-20.

3. Rao SM. A manual for the brief repeatable battery of neuropsychological tests in Multiple Sclerosis; 1991.

4. Benedict RH, Cookfair D, Gavett R, et al. Validity of the minimal assessment of cognitive function in multiple sclerosis (MACFIMS). J Int Neuropsychol Soc. 2006 Jul;12(4):549-58.

5. Vitkovitch M, Bishop S, Dancey C, Richards A. Stroop interference and negative priming in patients with multiple sclerosis. Neuropsychologia. 2002;40(9):1570-6.

6. Golden CJ. Stroop Colour and Word Test: A Manual for Clinical and Experimental Uses. Chicago, Illinois: Skoelting; 1978.

7. MacLeod CM. Half a century of research on the Stroop effect: an integrative review. Psychol Bull. 1991 Mar;109(2):163-203.

8. MacLeod CM, MacDonald PA. Interdimensional interference in the Stroop effect: uncovering the cognitive and neural anatomy of attention. Trends Cogn Sci. 2000 Oct 1;4(10):383-91.

9. Gazzaley A, Cooney JW, McEvoy K, Knight RT, D'Esposito M. Top-down enhancement and suppression of the magnitude and speed of neural activity. J Cogn Neurosci. 2005 Mar;17(3): 507-17.

10. Stroop JR. Studies of interference in serial verbal reaction. Clin Neuropsychol. 1935;11:87-90.

11. Golden CJ, Freshwater SM. Stroop Color and Word Test Adult Version. A manual for Clinical and Experimental Uses. Catalog No. 30150M ed. Nova Southeastern University: Stoelting; 2002.

12. Ivnik RJ, Smith GE, Lucas JA, Tangalos EG, Kokmen E, Petersen RC. Free and cued selective reminding test: MOANS norms. J Clin Exp Neuropsychol. 1997 Oct;19(5):676-91.

13. Steinberg B, Bieliauskas L. Introduction to the special edition: IQbased MOANS norms for multiple neuropsychological instruments. Clin Neuropsychol. 2005 Sep-Dec;19(3-4):277-9.

14. Graf P, Uttl B, Tuokko H. Color- and picture-word Stroop tests: performance changes in old age. J Clin Exp Neuropsychol. 1995 May;17(3):390-415.

15. Uttl B, Graf P. Color-Word Stroop test performance across the adult life span. J Clin Exp Neuropsychol. 1997 Jun;19(3):405-20. 
16. Ivnik RJ, Malec JF, Smith GE, Tangalos EG. Neuropsychological test norms above age 55: COWAT, VNT, MAE Token, WRAT-R Reading, AMNART, Stroop, TMT and JLO. Clin Neuropsychol. 1996(10):262-78.

17. Comalli PE, Jr., Wapner S, Werner H. Interference effects of Stroop color-word test in childhood, adulthood, and aging. J Genet Psychol. 1962 Mar;100:47-53.

18. Das JP. Changes in Stroop-Test responses as a function of mental age. Br J Soc Clin Psychol. 1970 Feb;9(1):68-73.

19. Foong J, Rozewicz L, Quaghebeur G, et al. Executive function in multiple sclerosis. The role of frontal lobe pathology. Brain. 1997 Jan;120 ( Pt 1):15-26.

20. Morey CC, Elliott EM, Wiggers J, Eaves SD, Shelton JT, Mall JT. Goal-neglect links Stroop interference with working memory capacity. Acta Psychol (Amst). Oct;141(2):250-60.

21. Strober L, Englert J, Munschauer F, Weinstock-Guttman B, Rao S, Benedict RH. Sensitivity of conventional memory tests in multiple sclerosis: comparing the Rao Brief Repeatable Neuropsychological Battery and the Minimal Assessment of Cognitive Function in MS. Mult Scler. 2009 Sep;15(9):1077-84.

22. Smith A. Symbol Digit Modalities Test. Manual. Los Angeles: Western Psychological Services; 1982.

23. Rao SM, Leo GJ, Bernardin L, Unverzagt F. Cognitive dysfunction in multiple sclerosis. I. Frequency, patterns, and prediction. Neurology. 1991 May;41(5):685-91.

24. Benedict RH, Fishman I, McClellan MM, Bakshi R, WeinstockGuttman B. Validity of the Beck Depression Inventory-Fast Screen in multiple sclerosis. Mult Scler. 2003 Aug;9(4):393-6.

25. Krupp LB, LaRocca NG, Muir-Nash J, Steinberg AD. The fatigue severity scale. Application to patients with multiple sclerosis and systemic lupus erythematosus. Arch Neurol. 1989 Oct;46(10): $1121-3$.

26. Blair JR, Spreen, O. Predicting premorbid IQ: A revision of the National Adult Reading Tes. Clinical Neuropscychologist. 1989; 2:129-36.

27. Strauss E, Sherman EMS, Spreen O. A Compendium of Neuropsychological Tests: Administration, Norms, and Commentary. 3rd ed. New York: Oxford University Press; 2006.

28. Benedict RH, Zivadinov R. Reliability and validity of neuropsychological screening and assessment strategies in MS. J Neurol. 2007 May;254 Suppl 2:II22-5.

29. Fischer JS, Rudick RA, Cutter GR, Reingold SC. The Multiple Sclerosis Functional Composite Measure (MSFC): an integrated approach to MS clinical outcome assessment. National MS Society Clinical Outcomes Assessment Task Force. Mult Scler. 1999 Aug;5(4):244-50.
30. Bobholz JA, Rao SM, Lobeck L, et al. fMRI study of episodic memory in relapsing-remitting MS: correlation with T2 lesion volume. Neurology. 2006 Nov 14;67(9):1640-5.

31. Rocca MA, Valsasina P, Ceccarelli A, et al. Structural and functional MRI correlates of Stroop control in benign MS. Hum Brain Mapp. 2009 Jan;30(1):276-90.

32. Rovaris M, Filippi M, Falautano M, et al. Relation between MR abnormalities and patterns of cognitive impairment in multiple sclerosis. Neurology. 1998 Jun;50(6): 1601-8.

33. Gadea M, Martinez-Bisbal MC, Marti-Bonmati L, et al. Spectroscopic axonal damage of the right locus coeruleus relates to selective attention impairment in early stage relapsingremitting multiple sclerosis. Brain. 2004 Jan;127(Pt 1):89-98.

34. Steinberg BA, Bieliauskas LA, Smith GE, Ivnik RJ. Mayo's Older Americans Normative Studies: Age- and IQ-Adjusted Norms for the Trail-Making Test, the Stroop Test, and MAE Controlled Oral Word Association Test. Clin Neuropsychol. 2005 Sep-Dec; 19(3-4):329-77.

35. Bodling AM, Denney DR, Lynch SG. Cognitive aging in patients with multiple sclerosis: a cross-sectional analysis of speeded processing. Arch Clin Neuropsychol. 2009 Dec;24(8):761-7.

36. Parmenter BA, Weinstock-Guttman B, Garg N, Munschauer F, Benedict RH. Screening for cognitive impairment in multiple sclerosis using the Symbol digit Modalities Test. Mult Scler. 2007 Jan;13(1):52-7.

37. Morrow SA, O'Connor PW, Polman $\mathrm{CH}$, et al. Evaluation of the symbol digit modalities test (SDMT) and MS neuropsychological screening questionnaire (MSNQ) in natalizumabtreated MS patients over 48 weeks. Mult Scler. Nov;16(11): 1385-92.

38. Benedict RH, Duquin JA, Jurgensen S, et al. Repeated assessment of neuropsychological deficits in multiple sclerosis using the Symbol Digit Modalities Test and the MS Neuropsychological Screening Questionnaire. Mult Scler. 2008 Aug;14(7):940-6.

39. Lynch SG, Dickerson KJ, Denney DR. Evaluating processing speed in multiple sclerosis: a comparison of two rapid serial processing measures. Clin Neuropsychol. Aug;24(6):963-76.

40. Denney DR, Lynch SG. The impact of multiple sclerosis on patients' performance on the Stroop Test: processing speed versus interference. J Int Neuropsychol Soc. 2009 May;15(3): 451-8.

41. Bodling AM, Denney DR, Lynch SG. Rapid serial processing in patients with multiple sclerosis: the role of peripheral deficits. J Int Neuropsychol Soc. 2008 Jul;14(4):646-50. 